\title{
Measurement of Tidal Volume during High- Frequency Jet Ventilation ${ }^{1}$
}

\author{
STUART A. WEISBERGER, WALDEMAR A. CARLO, JANIE M. FOUKE, \\ ROBERT L. CHATBURN, THOMAS TILLANDER, AND RICHARD J. MARTIN \\ Department of Pediatrics, Rainbow Babies and Children's Hospital and Department of Biomedical Engineering, \\ Case Western Reserve University, Cleveland, Ohio 44106
}

\begin{abstract}
The measurement of tidal volume during high-frequency jet ventilation is difficult due to the highfrequency components of the inspiratory flow. To validate tidal volume measured with a screen pneumotachograph placed on the expiratory limb, we simultaneously determined tidal volume with a body plethysmograph in seven anesthetized normal adult New Zealand rabbits before and after saline lung lavage. Four to six comparisons of tidal volume were obtained by varying peak inspiratory pressures at each combination of frequency $(120,240$, and 480 / $\mathrm{min})$ and inspiratory to expiratory time ratio $(1: 1,1: 3,1: 5$, 1:9). Overall, $90 \%$ of the tidal volumes measured with the pneumotachograph were within $10 \%$ of $1 \mathrm{ml}$ of the volumes determined with the plethysmograph, independent of frequency, inspiratory to expiratory time ratio, and lung compliance. There was unidirectional outward flow at the pneumotachograph during inspiration when both normal and saline lavaged lungs were being ventilated, suggesting a lack of gas entrainment. We conclude that a pneumotachograph on the expiratory limb may be used to measure tidal volume and gas entrainment in vivo during highfrequency jet ventilation. Determination of tidal volume may serve to optimize ventilator settings during highfrequency jet ventilation and facilitate an understanding of the mechanisms involved in gas exchange. (Pediatr Res 20: 45-48, 1986)
\end{abstract}

\section{Abbreviations}

HFJV, high-frequency jet ventilation

I:E, inspiratory to expiratory time ratio

High-frequency ventilation encompasses various new techniques of assisted ventilation currently being evaluated for use in adults and newborn infants. Although adequate or improved gas exchange during high-frequency ventilation may be accomplished at lower airway pressures than with conventional ventilation (1-4), the mechanism whereby gas exchange is accomplished is widely debated (5). During high-frequency oscillation tidal volumes less than dead space maintain adequate ventilation (6). During HFJV, tidal volume has been difficult to monitor in

Received June 24, 1985; accepted August 21, 1985.

Correspondence to Waldemar A. Carlo, M.D., Department of Pediatrics, Rainbow Babies and Children's Hospital, 2101 Adelbert Road, Cleveland, OH 44106.

Supported in part by research grants from the American Lung Association of Northern Ohio, American Lung Association of Ohio, and Board of Trustees of Rainbow Babies and Children's Hospital.

1 Presented in part at the Society for Pediatric Research, Washington, D.C., May 1985 and at the Annual Meeting of the American Thoracic Society, Anaheim, May 1985 . clinical situations because of high-frequency components in the flow signal.

Frantz and Close (7) used body plethysmography to measure tidal volume during HFJV in rabbits and Carlon et al. (8) utilized an ultrasonic spirometer in adults. Although plethysmography is an appropriate technique to measure ventilation, it does not lend itself to studies on critically ill ventilator-dependent patients. Carlon et al. (8) did not validate the ultrasonic spirometer with other accepted techniques for measuring tidal volumes. On the other hand, a pneumotachograph linear at the appropriate flows and with an adequate frequency response could be utilized clinically if its accuracy is validated. Therefore, in this study, tidal volumes obtained with a pneumotachograph placed on the expiratory arm of the ventilator were compared to those obtained simultaneously with a body plethysmograph.

\section{METHODS}

Tidal volumes were measured during HFJV in seven adult New Zealand white rabbits weighing 2.2 to $2.9 \mathrm{~kg}$. The rabbits were anesthetized with xylazine, $5 \mathrm{mg} / \mathrm{kg}$ intramuscular, followed by ketamine, $50 \mathrm{mg} / \mathrm{kg}$, intramuscular. Subsequent maintenance doses of ketamine, $25 \mathrm{mg} / \mathrm{kg}$, intramuscular were given as required. The rabbits were intubated with a $3.0-\mathrm{mm}$ internal diameter uncuffed endotracheal tube and the trachea was surgically exposed in order to secure a tie around it and avoid air leaks. The rabbit was then placed inside a body plethysmograph with an opening to provide ventilatory access for the endotracheal tube.

HFJV was administered utilizing a jet ventilator (4) with an electronic timer driving a solenoid valve that intermittently allowed release of a delivered gas mixture under high pressure through a narrow cannula ( $1.6 \mathrm{~mm}$ in these studies). The delivered gas mixture to the rabbits was nonhumidified $100 \%$ oxygen at room temperature. A Hans Rudolph (Hans Rudolph, Inc., Kansas City, MO) no. 4700 screen pneumotachograph and Validyne (MP-45-18, $\pm 5 \mathrm{~cm} \mathrm{H}_{2} \mathrm{O}$ ) pressure transducer (Validyne Engineering Corp., Northridge, CA) with a flat frequency response (within $5 \%$ ) to $40 \mathrm{~Hz}$ and linear from $0-100$ liter $/ \mathrm{min}$ were used to measure flows. The pneumotachograph was calibrated with a syringe from 5 to $50 \mathrm{ml}$ in 5 -ml increments. Use of $100 \% \mathrm{O}_{2}$ and $8 \% \mathrm{CO}_{2}$ did not affect the neumotachograph calibration. The pneumotachograph was positioned in the expiratory arm of the system (Fig. 1) directly above the jet cannula as recently described (9). The volumes measured during the expiratory phase of the jet cyle represent the volume passively expired by the lungs. In the absence of changes in functional residual capacity, this volume approximates the volume inflating the lungs during the inspiratory phase of the jet ventilator. Placement of the pneumotachograph in the expiratory arm also enabled documentation of the presence or absence of gas entrainent.

The flow signal of the pneumotachograph was sampled at 500 


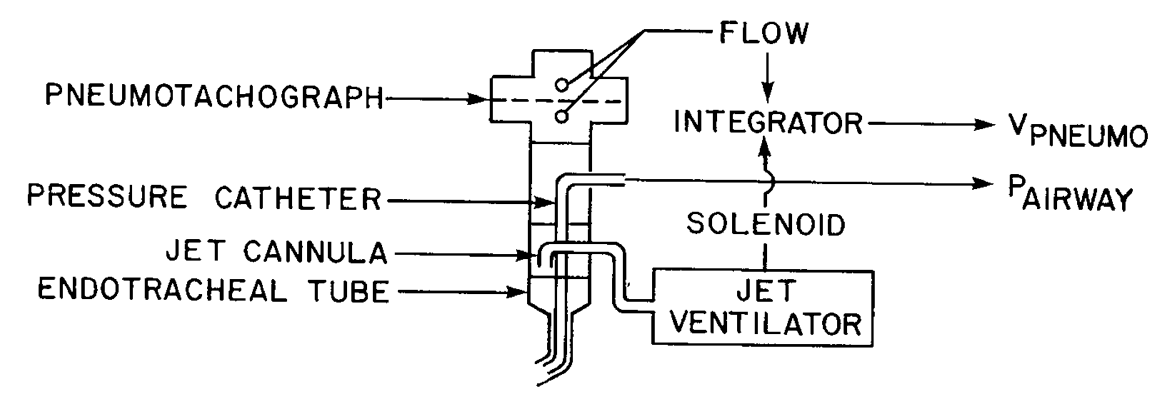

Fig. 1. Schematic demonstration of the pneumotachograph placed in the expiratory arm of the ventilator circuit.

$\mathrm{Hz}$ and digitally integrated using a PDP 11/34 computer (Digital Equipment Corp., Maynard, MA). Integration was initiated at the on and off electrical signals of the solenoid. This allowed a clear distinction to be made between the inspiratory and expiratory volume signals (Fig. 2). A 20-24 ms delay occurred between the generation of the electrical solenoid signal and the onset of flow into the rabbit. This delay was a variable included in the integration program. A 20 -liter aluminum pressure plethysmograph was used for comparison of measured tidal volumes. The frequency response of the plethysmograph was measured employing a system analogous to that of Jackson and Vinegar (10). A Hans-Rudolph no. 4700 screen pneumotachograph was positioned between an enclosed speaker and the plethysmograph. Displacement of the speaker produced changes in volume within the plethysmograph itself. These were measured by flow integration of the pneumotachograph. A Validyne (MP-45-18, $\pm 5 \mathrm{~cm}$ $\mathrm{H}_{2} \mathrm{O}$ ) transducer was used to detect corresponding pressure changes within the plethysmograph. Both the pneumotachograph and transducer had flat responses (within $5 \%$ ) beyond $40 \mathrm{~Hz}$. The plethysmograph itself showed a flat response (within 5\%) to $27 \mathrm{~Hz}$ with a slow roll-off up to $40 \mathrm{~Hz}$. The plethysmograph was calibrated with a syringe using volumes from 5 to $50 \mathrm{ml}$ in $5-\mathrm{ml}$ increments as well as with an oscillating pump utilizing volumes of 15 and $30 \mathrm{ml}$ delivered at frequencies from 5 to $8 \mathrm{~Hz}$. Plethysmograph temperatures during the studies did not vary by more than $0.5^{\circ} \mathrm{C}$.

Airway pressure was monitored with a $14 \mathrm{~cm}$ long 16 gauge air-filled polyvinyl catheter (Angiocath, Deseret Co., Salt Lake City, UT) placed inside the endotracheal tube and connected to a Validyne (MP-45-18, $\pm 50 \mathrm{~cm} \mathrm{H} \mathrm{H}_{2} \mathrm{O}$ ) transducer. The tip of the pressure catheter was $9 \mathrm{~cm}$ from the jet cannula opening. The frequency response of this pressure-catheter system was flat (within $5 \%$ ) to $10 \mathrm{~Hz}$. The catheter was also tested in a 1-liter enclosed container in which the pressure source was the jet ventilator at the rates and I:E ratios utilized in the in vivo studies. Pressure amplitude measured by the catheter was within $5 \%$ of that recorded by the reference transducer (Validyne).

Studies were performed at frequencies of 120,240 , and 480 cycles/min $(2,4$, and $8 \mathrm{~Hz})$ and I:E ratios of $1: 1,1: 3,1: 5$, and 1:9. Jet driving pressure was altered so as to vary peak inspiratory pressure from 5 to $35 \mathrm{~cm} \mathrm{H}_{2} \mathrm{O}$ at each combination of frequency and I:E ratio. Thus, for each rabbit, four to six pairs of volume measurements were then obtained per I:E ratio for each frequency. The lungs of the animals were then lavaged with 30 to $40 \mathrm{ml}$ of $37^{\circ} \mathrm{C}$ normal saline two to three times (11). Lung lavage decreased specific compliance from $1.33 \pm 0.27$ to $0.72 \pm 0.2$ $\mathrm{ml} \mathrm{cm} \mathrm{H}_{2} \mathrm{O}^{-1} \mathrm{~kg}^{-1}$. The same protocol of changes of frequencies, I:E ratio, and pressures was then repeated following lavage.

All data were recorded on a Gould (Model 260, Gould, Inc., Cleveland, $\mathrm{OH}$ ) six channel recorder. A sine wave input to all six channels showed a flat response (within $5 \%$ ) beyond $60 \mathrm{~Hz}$. One-way analyses of variance were utilized to determine if frequency, I:E ratio, or lung lavage had an effect on the accuracy of the pneumotachograph. Tidal volumes obtained with the pneumotachograph and the plethysmograph were also compared for each individual rabbit using linear regression.

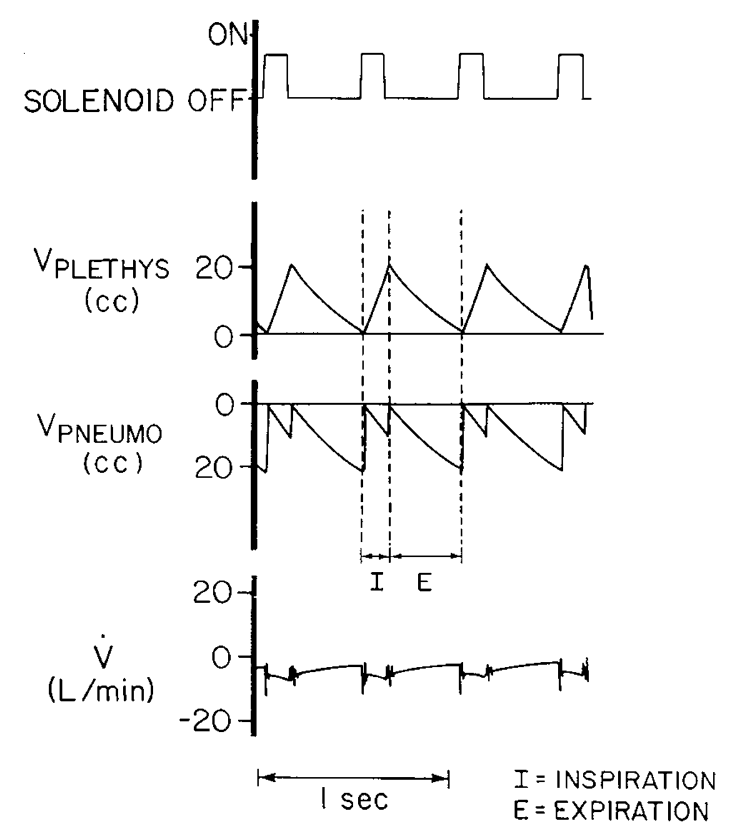

Fig. 2. Representative data in one rabbit during HFJV at a frequency of $120 / \mathrm{min}$ and I:E of $1: 3$. The on signal of the solenoid coincides with the inspiratory phase of the jet cycle. In this example, the expired volume determined by both the plethysmograph and the pneumotachograph was $20 \mathrm{ml}$. During the inspiratory phase both the flow ( $\dot{V})$ at the pneumotachograph as well as its integrated volume were in the negative direction suggesting lack of gas entrainment.

\section{RESULTS}

Tidal voumes obtained by varying driving pressure (and therefore, airway pressure) at different rates and I:E ratios ranged from 2 to $40 \mathrm{ml}$. There was a close relationship between volumes measured by the plethysmograph and pneumotachograph as demonstrated in Figure 3, which is a compilation of all the points obtained in the normally compliant lungs of the seven rabbits. Accuracy of the pneumotachograph was assessed by determining the percentage of volumes that were within $1 \mathrm{ml}$ or $10 \%$ of the volume determined by the plethysmograph. For each I:E ratio and frequency, the percentage of volume comparisons that met these criteria was calculated in each rabbit.

Overall, $90 \%$ (408 of 452) of the pneumotachograph measurements made in normally compliant lungs met the criteria of accuracy. In individual rabbits, the percentage of volume measurements classified as accurate ranged from 71 to $100 \%$. The percentage of accurate volume measurements for each rabbit was compared in terms of frequency and I:E ratio. Using separate one-way analysis of variance, there was no effect of frequency or I:E ratio on the accuracy of the volume measurements.

Lung lavage did not alter accuracy: $90 \%$ (381 of 425) of the volumes measured with the pneumotachograph in the lavaged rabbits were comparable to those of the plethysmograph. Com- 
parison of volumes in the lavaged rabbits via analysis of variance again showed no effect of frequency or I:E ratio. The results of a typical study in a single rabbit are demonstrated in Figures 4 and 5 by comparing volumes at different frequencies and I:E ratios, respectively, before and after lavage. Linear regressions were performed on the volume comparisons of the combined data for each individual rabbit before and after lung lavage. The $r$ value for the regressions ranged from 0.98 to 0.99 with a slope of 0.88 to 1.07 and standard error of the estimate of 0.46 to $1.0 \mathrm{ml}$.

The typical flow pattern obtained during HFJV is demonstrated in Figure 2. During the inspiratory phase of the cycle when the jet ventilator was on, flow was negative at the pneumotachograph indicating net flow out of the system and an apparent absence of entrainment. This was the case over the entire range of ventilator settings used in these in vivo studies.

\section{DISCUSSION}

The use of a screen pneumotachograph with a solenoid-triggered integrator placed in the expiratory arm of the jet ventilator system allowed us to determine tidal volumes during HFJV. This system proved to be consistently accurate when compared to a plethysmograph over a wide range of volumes ( 2 to $40 \mathrm{ml})$, I:E ratios (1:1 to 1:9), frequencies (120 to 480 ), and inspiratory times $(12$ to $250 \mathrm{msec}$ ) in rabbits with lungs of normal and decreased compliance.

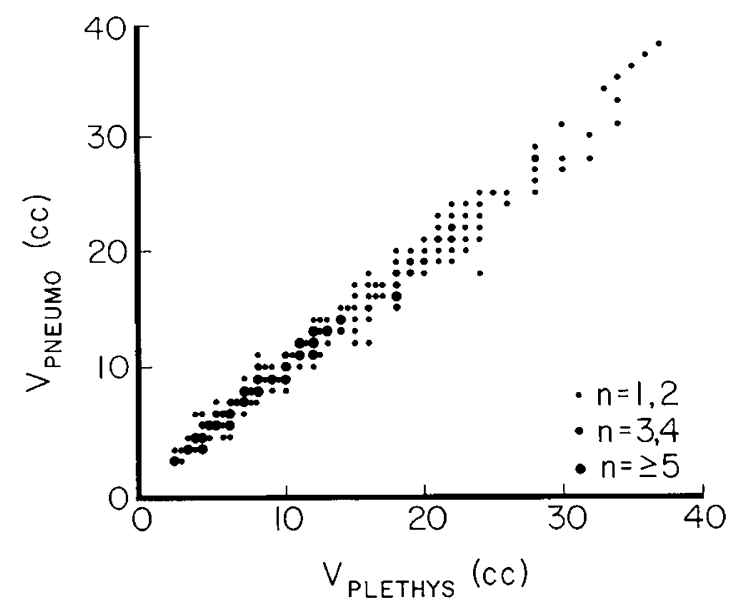

Fig. 3. Overall results of tidal volume comparisons in seven rabbits with lungs of normal compliance.
In order to demonstrate that tidal volumes obtained with the pneumotachograph were comparable to those obtained with the plethysmograph, we arbitrarily established accuracy criteria at $10 \%$ or $1 \mathrm{ml}$ since better resolution of the data was limited by the chart recording. We also compared the two techniques in each rabbit using regression analysis and documented a close linear relationship between the two methods of volume determination. Deviations from the line of unity of the volumes measured by the two systems were not consistent in any one direction. Chest wall dampening and gas compression would cause the body plethysmograph to have slightly underestimated the volume measured by the pneumotachograph. Variation in the time delay between the electrical signal and the injection of gas, gas characteristics (temperature and humidity), and respiratory quotient could also explain some of the discrepancies.

Placement of the pneumotachograph in the expiratory arm also offered an indirect method of determining presence or absence of entrainment by demonstrating the direction of airflow during the inspiratory phase. Recenty, Paloski et al. (9) used a similar technique to measure tidal volume, but placement of a one-way valve in the expiratory arm did not allow entrainment to occur. It has been generally assumed that entrained gas always contributes significantly to the inspired volume during HFJV (12). Recent in vitro data have demonstrated that the addition of a distal load (back pressure) may decrease or eliminate gas entrainment during HFJV (13). Our observations support this in vitro study and demonstrate that in small animals with normal or decreased compliance, gas entrainment during HFJV may not occur. The lack of entrainment observed during our current study may be due to high impedance caused by the small diameter of the airways and endotracheal tube as well as by the catheter placed inside the endotracheal tube. It is also possible that the lack of a bias flow with a positive pressure throughout inspiration may have reduced the likelihood of gas entrainment. These findings indicate that entrainment cannot always be assumed to occur during HFJV, especially in small animals and human infants. Humidification and oxygen delivery systems should therefore not be dependent on gas entrainment unless its presence is verified.

We have developed a system to measure tidal volumes during HFJV and shown that it is accurate when compared to body plethysmography. This system offers the possibility of evaluating volume delivery as well as gas entrainment during HFJV either in the laboratory or clinical setting. Monitoring of tidal volume, in addition to airway pressures and blood gases, should lead to a more rational approach to optimizing oxygenation and ventilation during HFJV in infants with respiratory distress.

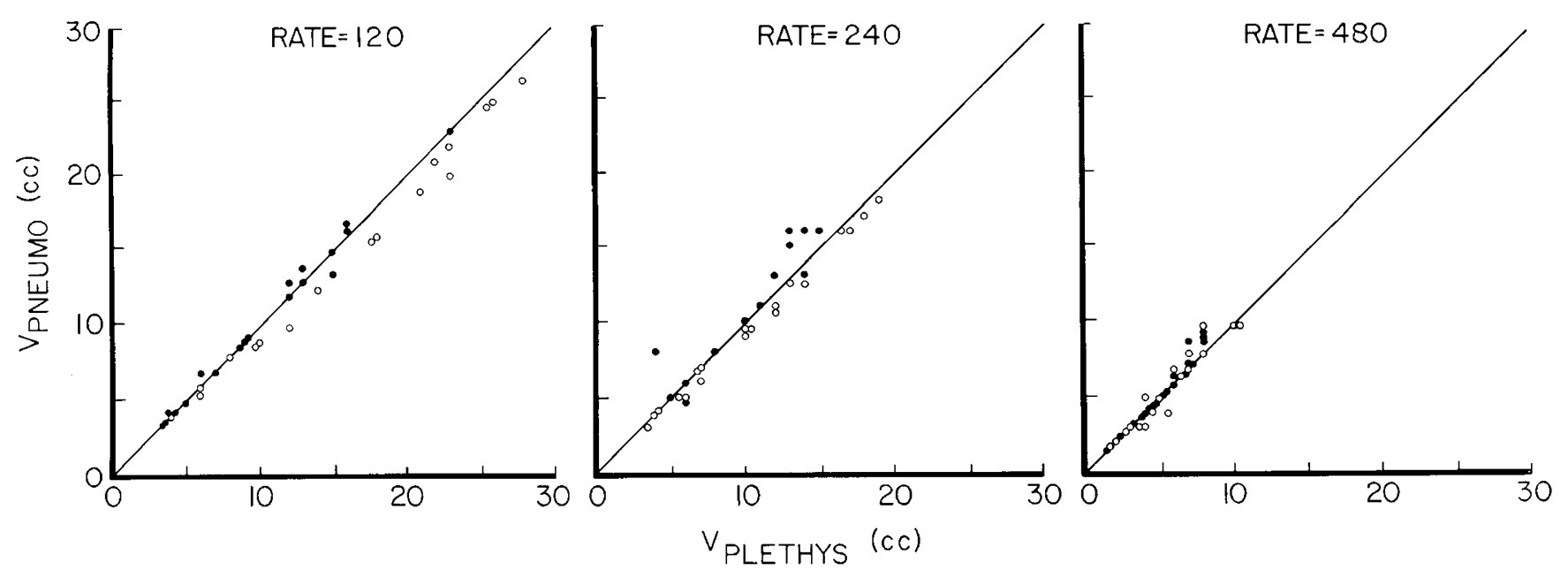

Fig. 4. Tidal volume comparisons in one rabbit at various ventilator frequencies. Open circles represent comparisons in normally compliant lungs and closed circles following saline lung lavage. Results are clustered along the line of identity (solid line). 


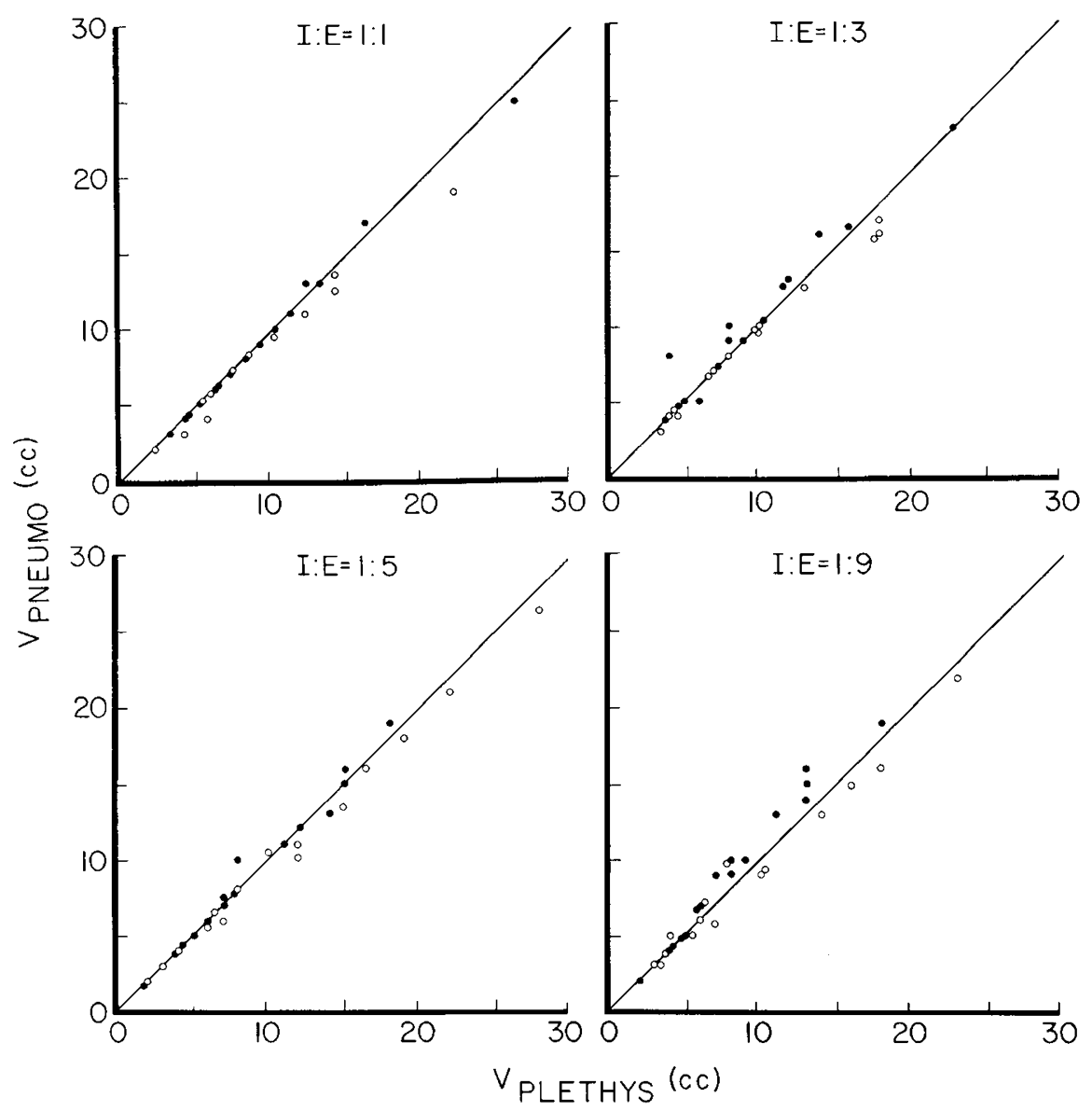

Fig. 5. Tidal volume comparisons in one rabbit at different I:E ratios with open circles representing normal compliance and closed circles decreased compliance. Volume comparisons are again shown along the line of identity.

Acknowledgments. The authors acknowledge David Goldthwait, Jr. and Jeff Teeter for their technical expertise and Claire Svet and Sandy Hartman for preparation of the manuscript.

\section{REFERENCES}

1. Marchack BE, Thompson WK, Duffy $P$, Miyaki T, Bryan MH, Bryan AC, Froese AB 1981 Treatment of RDS by high-frequency oscillatory ventilation: a preliminary report. J Pediatr 99:287-292

2. Pokora T, Bing D, Mammel M, Boros S 1983 Neonatal high-frequency jet ventilation. Pediatrics 72:27-32

3. Frantz ID, Werthammer J, Stark AR 1983 High-frequency ventilation in premature infants with lung disease: adequate gas exchange at low tracheal pressure. Pediatrics 71:483-488

4. Carlo WA, Chatburn RL, Martin RJ, Lough MD, Shivpuri CR, Anderson JV, Fanaroff AA 1984 Decrease in airway pressure during high-frequency jet ventilation in infants with respiratory distress syndrome. J Pediatr 104:101107

5. Chang HK 1984 Mechanisms of gas transport during ventilation by high frequency oscillation. J Appl Physiol 56:553-563

6. Slutsky AS, Kamm RD, Rossing TH, Loring SH, Lehr J, Shapiro AH, Ingram $\mathrm{RH} \mathrm{Jr} 1981$ Effects of frequency, tidal volume, and lung volume on $\mathrm{CO}_{2}$ elimination in dogs by high-frequency $(2-30 \mathrm{~Hz})$, low tidal volume ventilation. J Clin Invest 68:1475-1484

7. Frantz ID, Close RH 1985 Elevated lung volume and alveolar pressure during jet ventilation of rabbits. Am Rev Respir Dis 131:134-138

8. Carlon GC, Ray C, Griffin J, Midownik S, Groeger JS 1983 Tidal volume and airway pressure on high frequency jet ventilation. Crit Care Med 11:83-86

9. Paloski WH, Barie PS, Mullins RJ, Newell JC 1985 Effects of changing inspiratory to expiratory time ratio on carbon dioxide elimination during high-frequency jet ventilation. Am Rev Respir Dis 131:109-114

10. Jackson AC, Vinegar A 1979 A technique for measuring frequency response of pressure, volume and flow transducer. J Appl Physiol 47:462-466

11. Lachman B, Robertson B, Vogel J 1980 In vivo lung lavage as an experimental model of the respiratory distress syndrome. Acta Anaesth Scand 24:231-236

12. Gallagher TJ, Klain MM, Carlon GC 1982 Present status of high frequency ventilation. Crit Care Med 10:613-617

13. Hamilton LH, Londino JM, Linehan JH, Neu $J 1984$ Pediatric endotracheal tube design for high-frequency ventilation. Crit Care Med 12:988-993 